\title{
CARACTERIZACIÓN DEL ESPACIO GEOGRÁFICO DE LOS ASENTAMIENTOS PREHISPÁNICOS DEL PERÍODO MEDIO (500 D.C.-1000 D.C.) EN LOS VALLES OCCIDENTALES DEL ÁREA CENTRO SUR ANDINA. CAPLINA, TACNA (PERÚ) Y AZAPA, ARICA (CHILE)*
}

\author{
CHARACTERIZATION OF GEOGRAPHIC AREA OF SETTLEMENTS \\ OF PRE-COLUMBIAN PERIOD BETWEEN, IN LOW AREAS \\ OF AZAPA VALLEY AND THE VALLEY CAPLINA
}

\author{
Iván Muñoz Ovalle**, Oscar Corvacho Ganahin ${ }^{* * *}$ y Jesús Gordillo Begazo ${ }^{* * * *}$
}

\begin{abstract}
Se presenta un análisis de las condiciones geográficas de los espacios ocupados por asentamientos humanos prehispánicos durante el Periodo Medio para las zonas bajas del valle de Azapa, Arica (Chile), y media del valle de Caplina, Tacna (Perú). El trabajo analiza comparativamente distintas características territoriales (distribución espacial, pendientes, altimetría, área de ocupación, proximidad, red de drenaje y capacidad de uso mayor de suelo) asociadas a los patrones de asentamiento presentados en ambos valles. Los resultados muestran las similitudes y diferencias observadas entre ambas zonas geográficas, destacando la mayor complejidad del sistema de ocupación presentado en el valle de Azapa y la predominancia de asentamientos ubicados en sectores con bajas pendientes. De igual manera, se evidencia una considerable presencia de sitios arqueológicos sobre zonas aledañas a la red de drenaje y una gran vinculación espacial a suelos con buenas aptitudes para el desarrollo de la agricultura, en ambos valles.

Palabras claves: Valle de Azapa, ocupación espacial, asentamientos prehispánicos, valle medio del río Caplina.
\end{abstract}

An analysis of the geographical conditions of the spaces occupied by pre-Hispanic settlements during the Middle period for downstream areas Azapa Valley, Arica (Chile) and mean Caplina Valley, Tacna (Peru) is presented. The paper analyzes different territorial characteristics (spatial distribution, slope, elevation, area of occupancy, proximity, drainage and usability May floor) associated with settlement patterns presented in both valleys. The results show the similarities and differences observed between the two geographical areas, highlighting the increased complexity of the system of occupation presented in the Azapa Valley and the predominance of settlements located in areas with low slopes. Similarly, evidenced a strong presence of archaeological sites on areas surrounding the drainage network and a spatial link to soils with good skills for the development of agriculture in both valleys.

Key words: Azapa Valley, spatial occupation, pre-Hispanic settlements, the Caplina River Valley.

\section{Introducción}

Diversos autores destacan el rol altamente determinante que ha desempeñado a lo largo de la historia el medio geográfico en la forma de disposición humana sobre el territorio (Clark, 1980; Segrelles, 2002; Sugiura 2005). Es común que factores como la presencia de depósitos a pie de ladera, pendientes suaves, suelos relativamente fértiles y disponibilidad de agua, sean considerados condiciones propicias para el establecimiento humano en un espacio determinado (Botero,
León, y Moreno 1989), porque es razonable que las comunidades humanas tiendan a privilegiar condiciones que faciliten la toma de decisiones para poder cumplir las exigencias inherentes al desarrollo habitual de la vida en sociedad de la manera más favorablemente posible.

En este sentido, la ocupación del espacio por las sociedades humanas constituye un complejo sistema de interrelaciones donde el medio físico ofrecerá oportunidades y limitaciones a las comunidades para poder satisfacer sus necesidades, dependiendo de las distintas características y capacidades de

\footnotetext{
* Resultado del proyecto FONDECYT No 1130249.

** Universidad de Tarapacá, Departamento de Antropología. Arica, Chile. Correo electrónico: imunoz@uta.cl

*** Universidad de Tarapacá, Departamento de Ciencias Históricas y Geográficas. Arica, Chile. Correo electrónico: o.corvacho. ganahin@gmail.com

**** Universidad Privada de Tacna, Proyecto de Investigación arqueológico MOQI. Tacna, Perú. Correo electrónico: jpg1801@ hotmail.com
} 
adaptación que presente cada grupo humano que entra en contacto con un ambiente determinado (Córdova 2002).

Considerando las diversas zonas geográficas presentes alrededor del mundo, los valles deben ubicarse entre las más atractivas para el desarrollo de la vida humana, estas geoformas del relieve agrupan factores como la presencia de agua (con diversos estados y disponibilidad), sectores de terrazas fluviales con bajas pendientes, llanuras aluviales y cauces (con presencia de flujos de agua permanentes e intermitentes) que en conjunto configuran espacios altamente atractivos para la ocupación humana (Venegas 2007). Estas condiciones se han visto documentadas y reflejadas en el transcurso del tiempo con la presencia casi infaltable de sociedades humanas sedentarias asentadas en los diversos valles de Latinoamérica desde el periodo formativo, prefiriendo estos sectores por sobre la costa y la cordillera (Llagostera 1999), dando cuenta así de la estrechas interrelaciones históricas establecidas entre las sociedades y estos espacios geográficos complejos.

En el sur del Perú y norte de Chile se encuentran ubicados los valles fértiles de Caplina y Azapa. Estudios documentan y registran la existencia de diversas sociedades asentadas en estos sectores durante distintos períodos de la historia (Santoro 1980; Rivera 1983; Focacci 1990; Goldstein 1995-1996; Gordillo 1993; Lumbreras 1999; Muñoz y Zalaquett 2011 y 2015), no obstante, existe una carencia de información respecto de los patrones de ocupación presentados por las sociedades originarias que se ubicaron en estos valles.

En consecuencia, el trabajo pretende establecer el patrón de asentamiento presentado en ambas zonas durante el Periodo Medio, por medio del análisis comparativo de distintas condiciones geográficas asociadas a las áreas de ocupación observadas en el sector medio del valle del río Caplina y bajo del valle de Azapa, producto de prospecciones arqueológicas realizadas en ambos sectores.

\section{Descripción general del valle medio del río Caplina y Azapa}

El área de estudio del valle Caplina, ubicada a $25 \mathrm{~km}$ de la desembocadura del río, corresponde al sector geográfico del sur del Perú que comprende la parte baja de la cuenca del río Caplina ubicada en la sección político-administrativa del departamento de Tacna en la provincia del mismo nombre (Cruz
2010). Presenta un clima seco con temperatura anual promedio cercana a $17,55^{\circ} \mathrm{C}$, registrando máximas de $24{ }^{\circ} \mathrm{C}$ (marzo) y mínimas que van alrededor de $13,4{ }^{\circ} \mathrm{C}$ en los meses de invierno (julio), la humedad relativa promedio es del $76 \%$, alcanzando máximas de $88 \%$ en septiembre y mínimas cercanas al $63 \%$ en enero. La precipitación presenta un promedio anual cercano a los $0,8 \mathrm{~mm}$, alcanzando sus máximos valores entre los meses de julio y septiembre (Instituto Nacional de Recursos Naturales [IRENA] 1992).

Existe un vigoroso desarrollo de la actividad agrícola en la que se distinguen preferentemente cultivos como vid, árboles frutales, zapallo, alfalfa, olivo, papa, maíz choclo, maíz chala, tomate, haba, arveja entre otros (Cruz 2010), características que dan cuenta de las buenas condiciones topoclimáticas que posee esta zona.

En el valle de Azapa el área de reconocimiento se extiende desde el litoral y desembocadura del río San José hasta el kilómetro 18, sector Cabuza. Emplazado en la ciudad de Arica en el extremo norte de Chile, el valle de Azapa se caracteriza por presentar un clima desértico, con temperaturas mensuales que oscilan entre los 14 y $25 \mathrm{C}^{\circ}$, humedad relativa en torno al $70 \%$ y precipitaciones no superiores a $1 \mathrm{~mm}$ anual. Con presencia de suelos muy fértiles y aptos para el desarrollo de la actividad agrícola en este valle se pueden identificar diversas especies vegetales como ají, berenjena, lechuga, pepino, pimiento, porotos verdes, tomates, zapallo italiano, algodonero, alfalfa, olivo, caña de azúcar, y árboles frutales como naranjos, chirimoyo, limas, duraznero, ciruelos entre otros (Sánchez y Morales 1990; Hidalgo 2004; Torres y Acevedo 2008; González et al. 2013). En este sentido, el valle de Azapa cuenta con condiciones de agua, suelo y clima óptimas para el desarrollo de la actividad agrícola durante todo el año.

\section{Metodología}

Mediante levantamiento de información arqueológica previa se documentó el hallazgo de siete asentamientos dentro de una extensión aproximada de diez kilómetros en la sección media del valle del río Caplina, los sitios corresponden a Cristo Rey (C2), Mogollo 1 (C6), Copare 4 (C10), Mogollo 2 (C12), Cerro de Para 1(C13), Cerro de Para 2 (C14) y Mogollo Sur 1 (C40). Para el valle de Azapa el inventario y la prospección 
arqueológica abarcó desde el litoral de la ciudad de Arica y desembocadura del río San José, hasta el sector de Cabuza, kilómetro 18 del valle de Azapa; los sitios prospectados corresponden a 41 agrupados en cinco "áreas de influencia o nodos de concentración", determinados a partir de la ubicación del sitio identificado y su relación con manantiales y nacientes catastrados a lo largo del área de estudio; los nodos definidos han sido identificados como: A, B, C, D y E ${ }^{1}$.

El contexto geográfico se abordó como condicionante del patrón de asentamiento, considerando las siguientes propiedades del espacio asociadas a los emplazamientos estudiados: modelo de distribución espacial de los sitios, red de drenaje, pendientes, hipsometría (altitud), área de ocupación, proximidad y capacidad de uso mayor del suelo.

Para la distribución de sitios se trabajó sobre la base de una imagen satelital Quickbird de 2006 y una ASTER GDEM, generando un modelo de elevación digital (DEM). Se interpretó visualmente vías secundarias y zonas de emplazamiento, además se superpuso la localización de los sitios en el área mediante puntos de referencia espacial (GPS). Para la pendiente se trabajó sobre la base de un DEM; para ambas áreas estudiadas las pendientes fueron clasificadas en cinco clases que posibilitaran observar las disímiles condiciones para la habitabilidad de los diversos emplazamientos. En relación con la altitud se trabajó con la espacialización de los sitios arqueológicos y generación de curvas de nivel, contrastadas con información bibliográfica de elevación presentada en la tesis "Catastro, Inventario y Evaluación de Sitios Arqueológicos en el Valle Medio del Río Caplina-Tacna" (Gordillo 1993) y mapas de registros de sitios arqueológicos del valle de Azapa y costa de Arica, Oficina de Catalogación, Museo de San Miguel de Azapa, Depto. de Antropología (Dauelsberg 1995[1959]; Espoueys 1974). Para el área de ocupación se trabajó con el cálculo de áreas específicas mediante el software ARCGIS 10.2 y análisis comparativo con los valores presentados en la tesis "Catastro, Inventario y Evaluación de Sitios Arqueológicos en el Valle Medio del Río Caplina-Tacna" (Gordillo, ob. Cit.) y con información proporcionada por Muñoz y Zalaquett (2011 y 2015); de igual manera, para definir los tipos de sitios se tomó la información bibliográfica tanto para el valle de Caplina (Gordillo, ob. cit) como para el valle de Azapa (Muñoz y Zalaquett, 2011 y 2015). En cuanto a la proximidad entre los asentamientos, sitios y nodos, se hizo una estimación mediante software SIG de las distancias radiales que presentaron las unidades entre ellas. En relación con la red de drenaje principal tanto para Azapa como Caplina se trabajó con la superposición de información de la red hídrica del valle medio de los ríos Caplina y San José. Para la capacidad de uso mayor de las tierras se utilizó información georreferenciada sobre las series de suelos existentes en el sector bajo de la cuenca del río Caplina, y el valle de Azapa, obtenidas a partir de mapas de serie de suelos presentados en el "Inventario Nacional de Tierras del Perú" (ONER, 1981) para el caso de Tacna, y de los "Estudios Agronómicos Básicos de los Valles de Lluta, Azapa, Vitor y Camarones" (DOH, 2002), para Azapa.

\section{Resultados}

\section{Distribución de los sitios arqueológicos en el valle medio de los ríos Caplina y Azapa}

En el valle medio de Caplina se observa la distribución de los sitios arqueológicos a lo largo de aproximadamente 10,2 km de longitud, con dirección noreste suroeste. Los sitios C13 y C14 se emplazan en la ladera de exposición sureste de la divisoria de aguas oeste de la cuenca, a diferencia del resto que lo hace siguiendo un patrón longitudinal concordante con la llanura aluvial del área (Figura 1).

Para el caso de Azapa los sitios se presentan diseminados a lo largo de $18 \mathrm{~km}$ aproximadamente con orientación sureste noroeste ajustándose a la morfología del valle. Se observa un patrón de distribución espacial ampliamente relacionado con la presencia de manantiales permanentes e intermitentes presentes a lo largo del área de estudio (figura 2), individualmente la presencia de emplazamientos predomina en sectores asociados a la llanura aluvial y terrazas fluviales presentes en el valle, agrupados, los sitios reconocidos presentan una marcada segmentación espacial exhibida en cinco áreas de concentración marcadamente diferenciadas.

\section{Pendientes del terreno}

Los asentamientos prehispánicos en el valle de Caplina presentan un emplazamiento preferente hacia sectores con baja pendiente topográfica (menor a $6^{\circ}$ ), salvo $\mathrm{C} 13$ y $\mathrm{C} 14$ que se localizan en una 


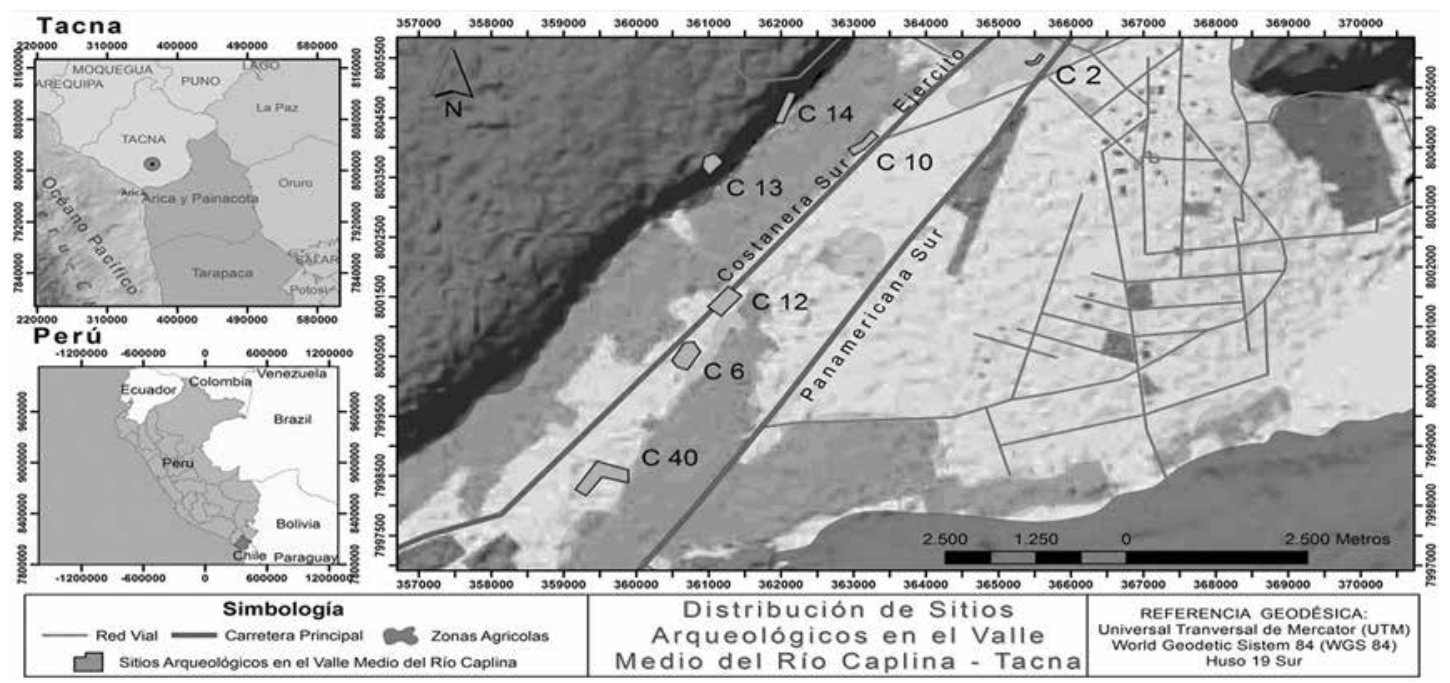

Figura 1. Ciudad de Tacna - Sector bajo cuenca del río Caplina.

sección con valores superiores a $16^{\circ}$ de inclinación (Figura 3). Los rasgos esperados para asentamientos humanos insertos dentro del contexto geográfico de una cuenca hidrográfica es la tendencia a asentarse preferentemente en zonas de llanura aluvial (del Moral 1999) y por tanto con presencia de pendientes topográficas muy bajas.

Los sitios reconocidos en el valle de Azapa muestran una tendencia a la ocupación de espacios con pendiente suave de entre cero a diez grados, pero con la particularidad de situarse aledaños a zonas de mayor elevación y pendiente más irregular. Individualmente, solo "Borde Terraza Chinchorro 3" y "Az-143" escapan a la condición general de ubicación próxima a sectores de pendiente pronunciada (superior a $16^{\circ}$ de inclinación) que presentan los sitios prospectados. En este contexto es posible señalar que el patrón de ocupación general asociado al factor pendiente en el valle de Azapa presenta una evidente tendencia hacia los sectores planos no abiertos, es decir, colindantes o cercanos a zonas de mayores pendientes y elevación (Figura 4).

\section{Altimetría}

En relación con la altitud, los asentamientos del valle de Caplina se extienden sobre las secciones más bajas del área analizada, fluctuando entre los 270 a 480 msm. Los sitios C2, C10, C12, C6 y C40 se diseminan a lo largo de la llanura aluvial presentando valores decrecientes de manera correlativa, desde el sitio C2 con 480 a C40 con ubicación a una altitud menor a los 300 metros, por tanto existe una diferencia de 180 metros de altitud entre el sitio arqueológico ubicado en el extremo noreste (C2) y C40 emplazado en el extremo suroeste del área. Para los sitios C13 y C14 los valores altitudinales fluctúan entre los 420 y $480 \mathrm{msm}$, debido a la ubicación en ladera que condiciona los valores de altitud a amplias variaciones entre las distintas zonas del área de ocupación espacial que presentan los sitios (Figura 5).

Para el valle de Azapa la mayor cantidad de yacimientos reconocidos y la distancia entre los emplazamientos desde el sector litoral hasta el interior del valle hacen que los valores altitudinales a los que se encuentran vinculados los distintos sitios presenten fluctuaciones de hasta 686 metros, como se manifiesta en el caso de Borde Terraza Chinchorro con emplazamiento a los 14 metros y Alto Cabuza con 700 sobre el nivel del mar (Figuras 2 y 6 ).

La sección media del área de estudio, en Azapa, es la que aglomera la mayor cantidad de sitios correspondiendo al nodo B (Figura 2), este presenta en los sectores más bajos valores altitudinales de 222 metros y de hasta 625 en las zonas con mayor altitud. Para el caso de las secciones con mayores y menores valores altimétricos, nodo $\mathrm{A}$ y $\mathrm{E}$, respectivamente, la cantidad de sitios individuales agrupados es menor, para el nodo E que alcanza una altitud máxima aproximada de 220 metros la cantidad de yacimientos reconocidos fueron dos (Playa Miller 9 


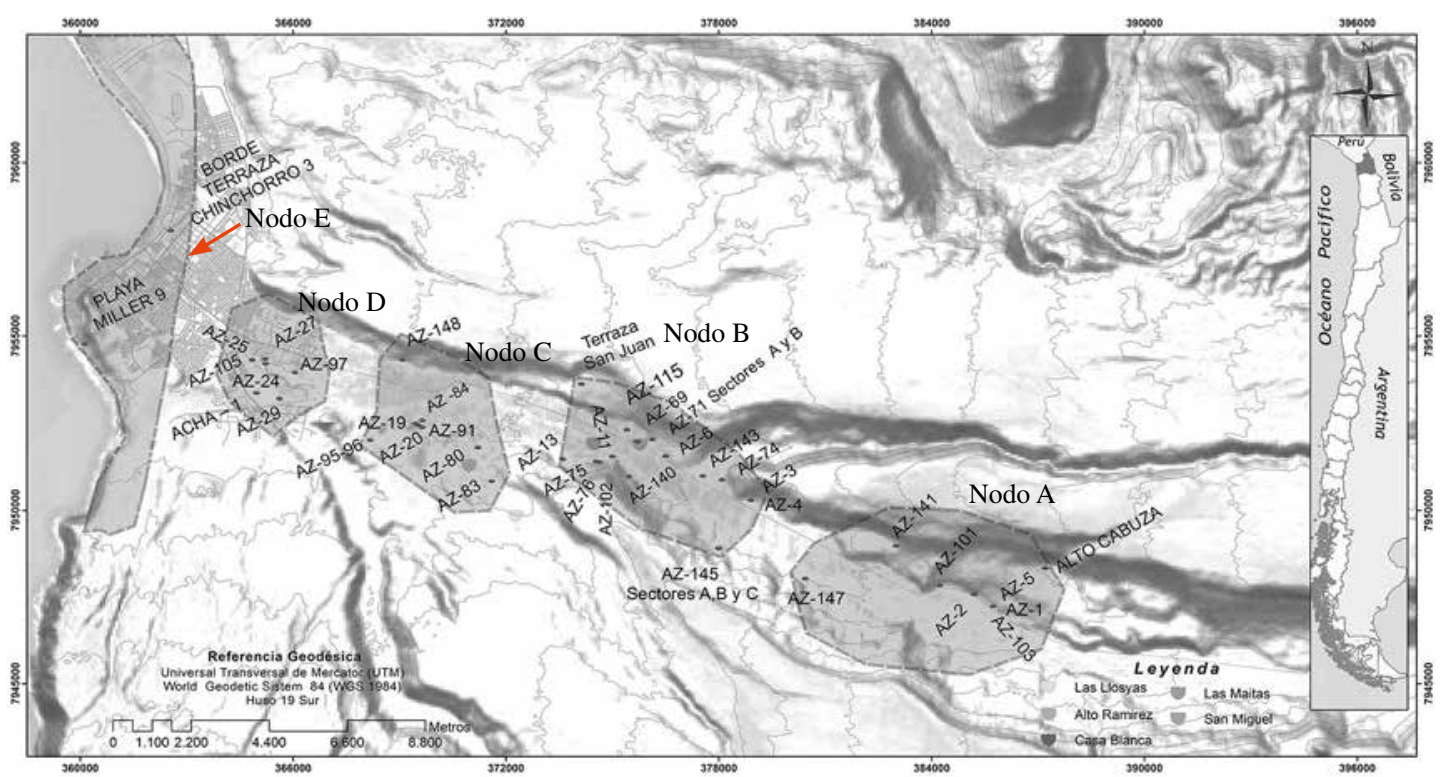

Figura 2. Ciudad de Arica - Sector bajo valle de Azapa.

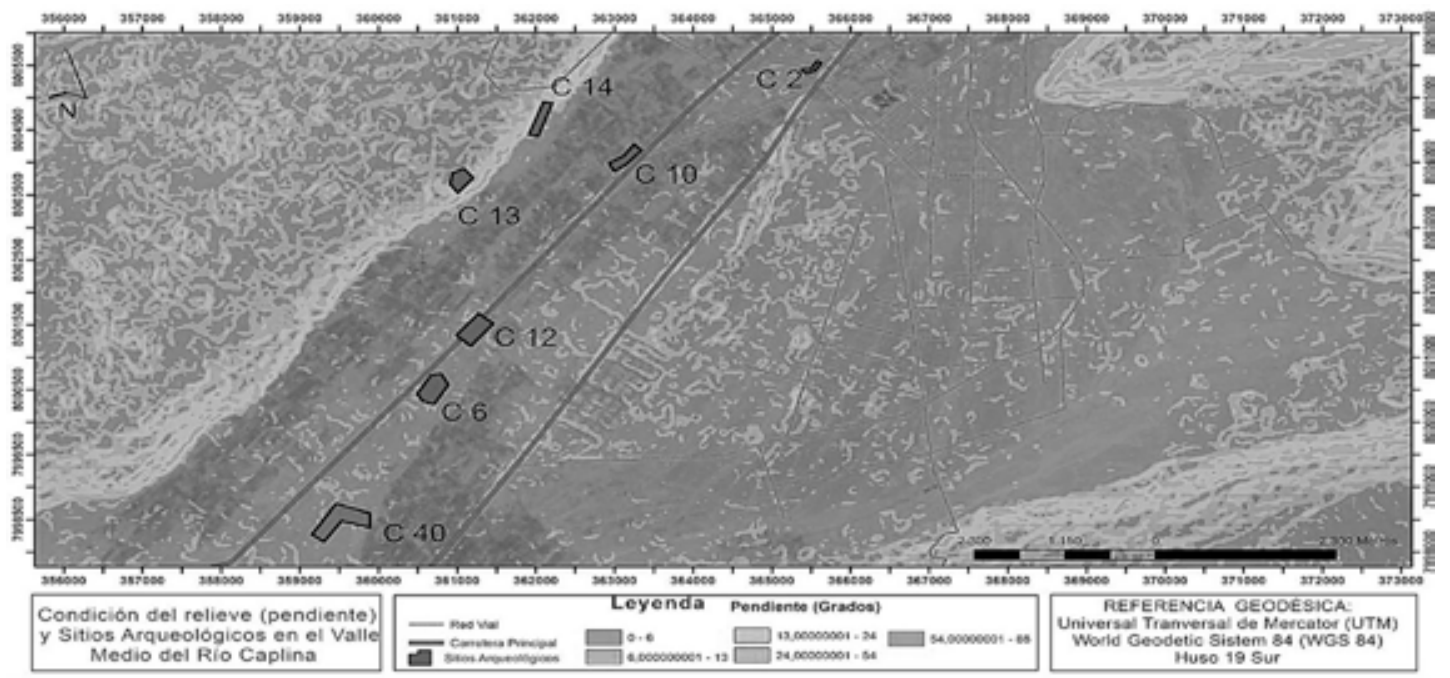

Figura 3. Pendientes del relieve - valle medio del río Caplina.

y Borde Terraza Chinchorro 3), mientras que para el "nodo A" con valores altitudinales máximos superiores a los 700 metros los sitios suman ocho (Az-1, Az-2, Az-5, Az-101, Az-103, Az-141, AZ-147 y Alto Cabuza).

\section{Área de ocupación}

El área de ocupación de los asentamientos del valle de Caplina presenta un patrón con dos secciones notoriamente diferenciadas, hacia el sector noreste los sitios C2, C10, C13 y C14 presentan un área de ocupación menor que no supera las siete hectáreas, mientras que en la sección baja o suroeste C12, C6, C40 se presentan áreas de ocupación mayor, con valores que van desde 10,5 hasta 20,3 hectáreas. Por lo demás, los sitios ubicados en los sectores más extremos, C2 al noreste y C40 en el suroeste, presentan la mayor diferencia en áreas de ocupación (Figura 7). 


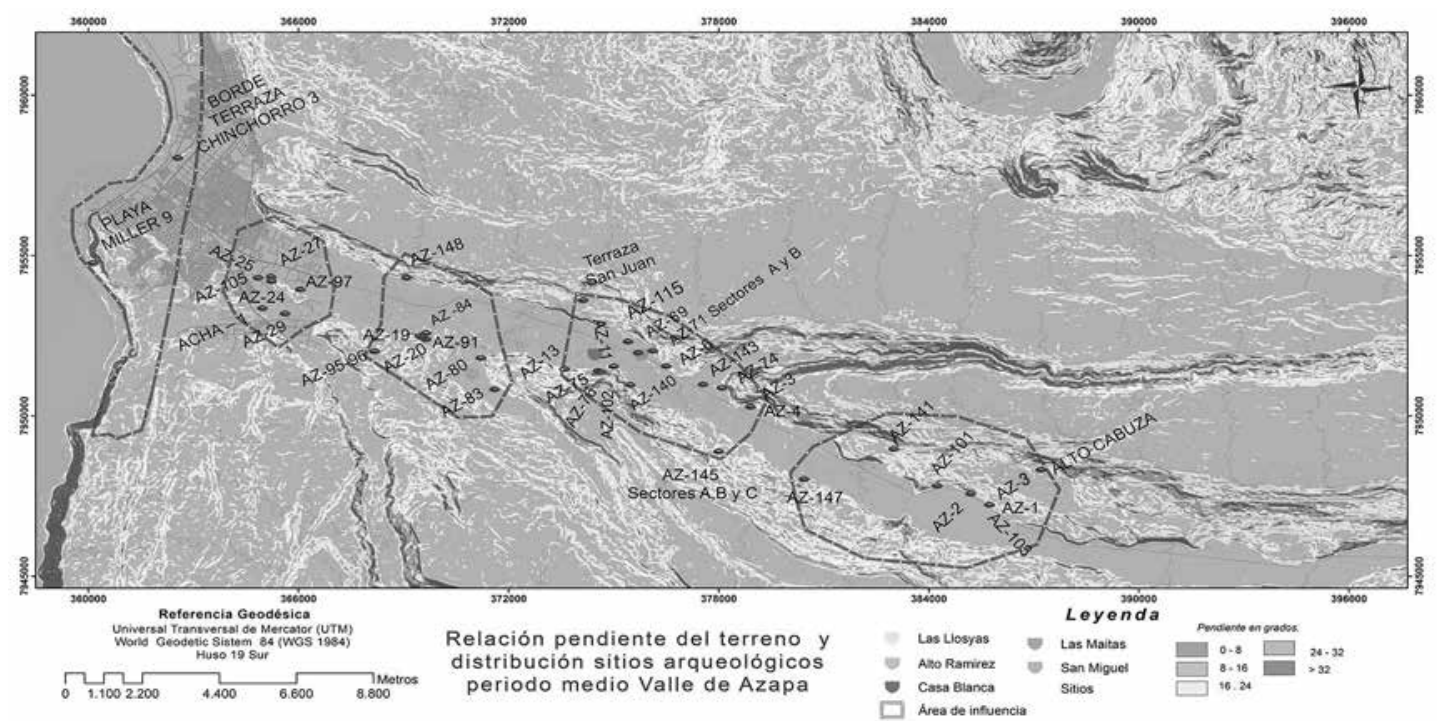

Figura 4. Pendientes del relieve - valle de Azapa.

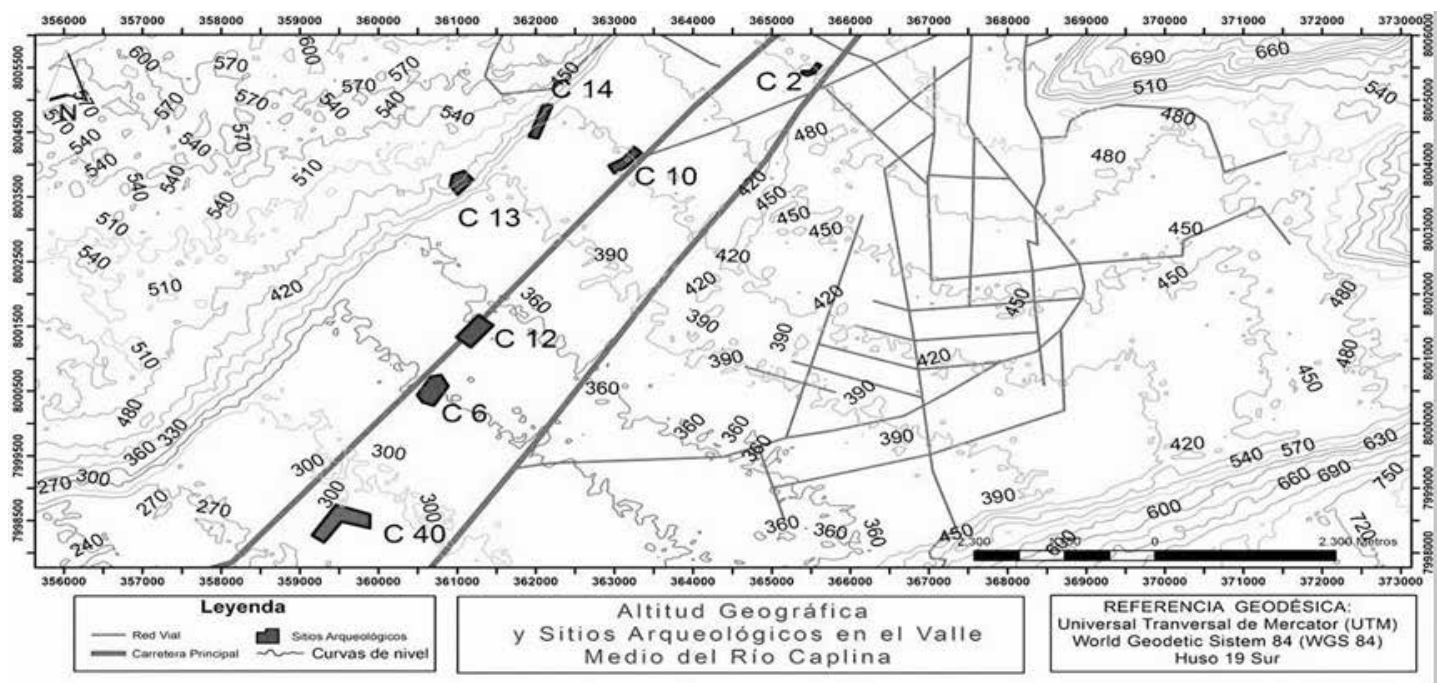

Figura 5. Altimetría Sección media valle del río Caplina.

Para el caso de Azapa, las cinco macrounidades o nodos de concentración en las que se agrupan los distintos sitios presentan áreas de ocupación mayores en las secciones extremas A y E, no obstante, son las que agrupan la menor cantidad de yacimientos individuales reconocidos, sumando diez entre ambas. El nodo con menor área de ocupación es el D, que agrupa siete sitios individuales reconocidos con 907 hectáreas, mientras que para los nodos intermedios B y $\mathrm{C}$ que contienen 24 sitios en total, los espacios ocupados alcanzan las 1.822 y 1.393 hectáreas, respectivamente (Figura 8).

\section{Distancia (proximidad)}

El análisis de proximidad espacial entre los distintos sitios arqueológicos emplazados en el valle medio del río Caplina presenta los siguientes resultados: a) los sitios extremos ( $\mathrm{C} 2$ noreste y $\mathrm{C} 40$ suroeste) exhiben las mayores distancias en relación con los sitios arqueológicos más próximos; b) los sitios con 


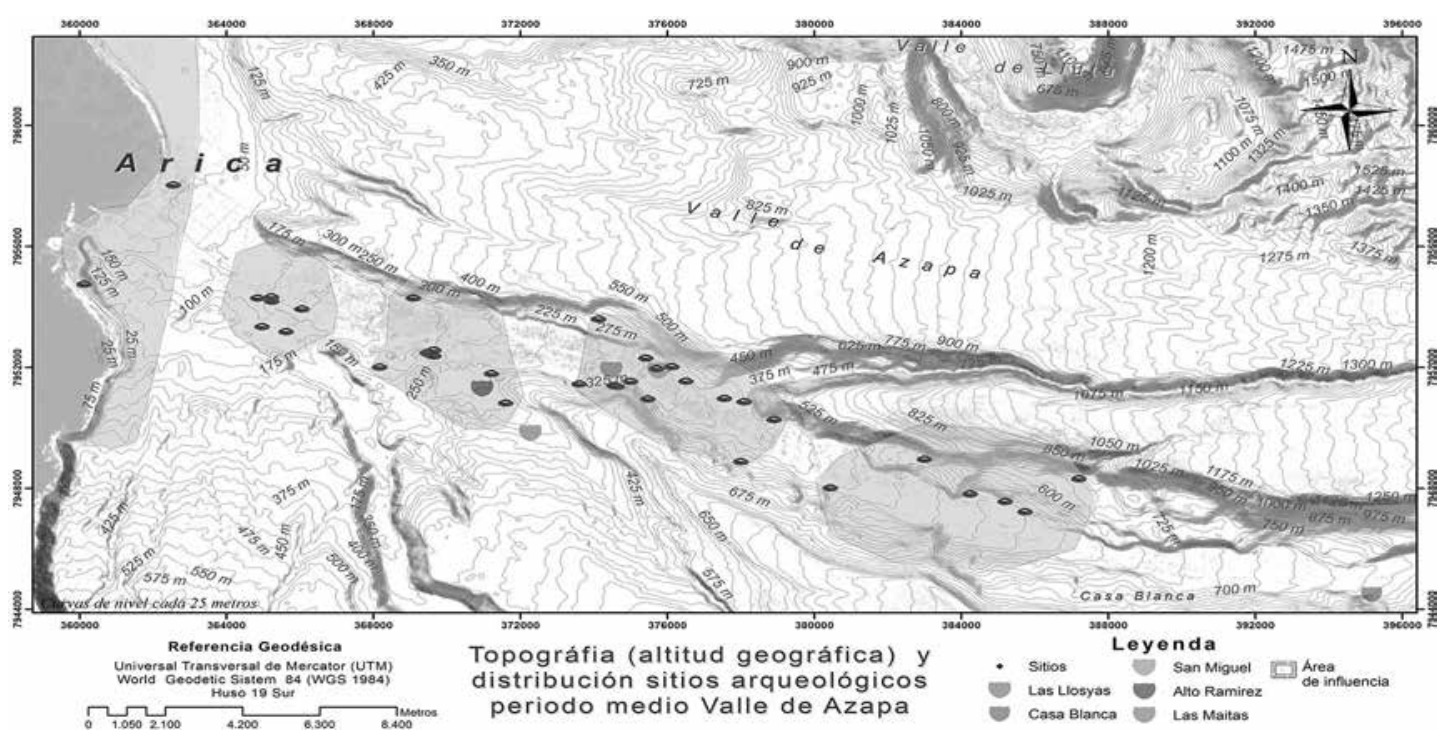

Figura 6. Altimetría Sección baja del valle de Azapa.

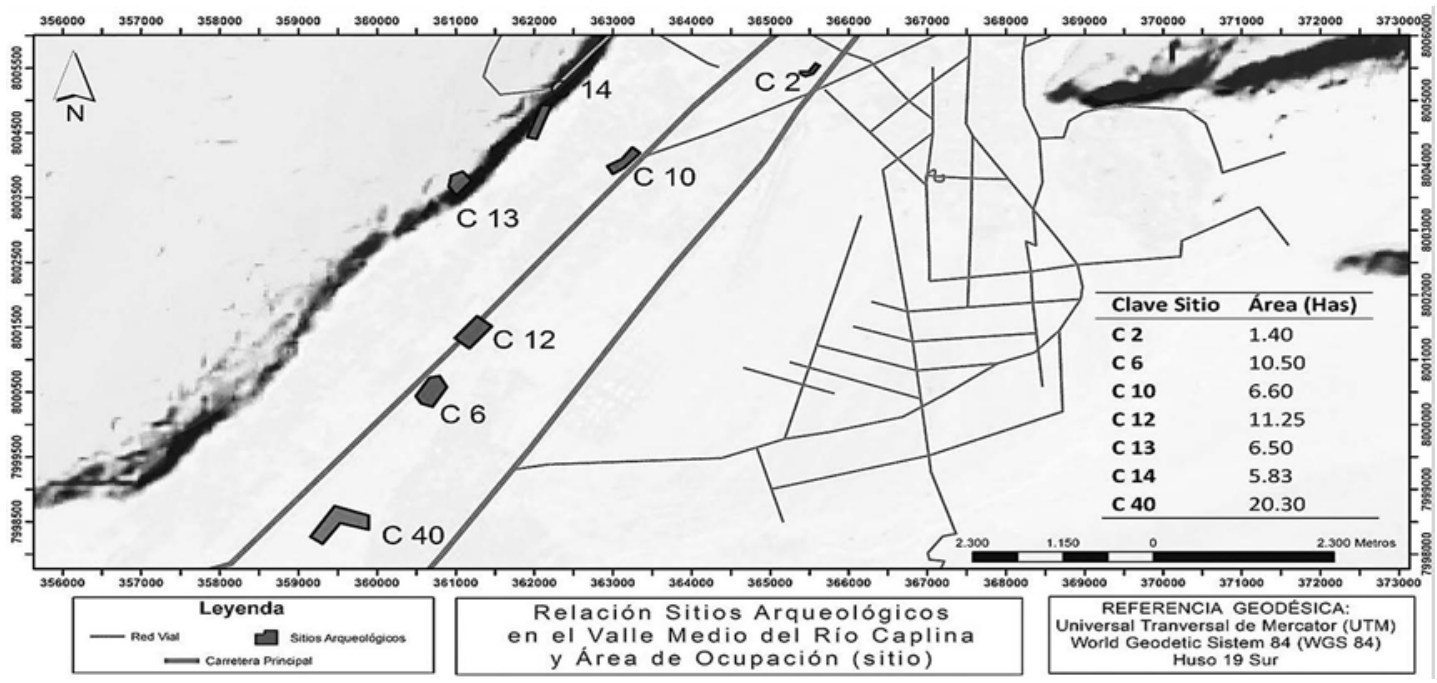

Figura 7. Área de ocupación sitios valle medio del río Caplina.

ubicación intermedia (C6, C10, C12, C13 y C14) presentan distancias variables que van desde los 569 a los 989 metros; c) los sitios que presentan mayor cercanía son C6 y C12, de tipo doméstico y cementerial doméstico, respectivamente con 569 metros de distancia y d) el sitio con mayor distancia (lejanía) es C2 y corresponde a un cementerio (Figura 9), ubicado a 2.408 metros de su similar más cercano.

En el valle de Azapa, en las cinco áreas arqueológicas (nodos) identificadas se observan distancias similares, los nodos extremos A y E se presentan más distantes con radios de 1.605 y 1.500 metros, respectivamente. Las secciones intermedias, nodos B, C y D se muestran más homogéneas con diferencias en distancias no superiores a 40 metros, los nodos $\mathrm{B}$ y C presentan la misma proximidad de 1.397 metros a la redonda, mientras que el nodo B no presenta contacto con otra unidad arqueológica en un radio aproximado de 1.437 metros (Figura 10). 


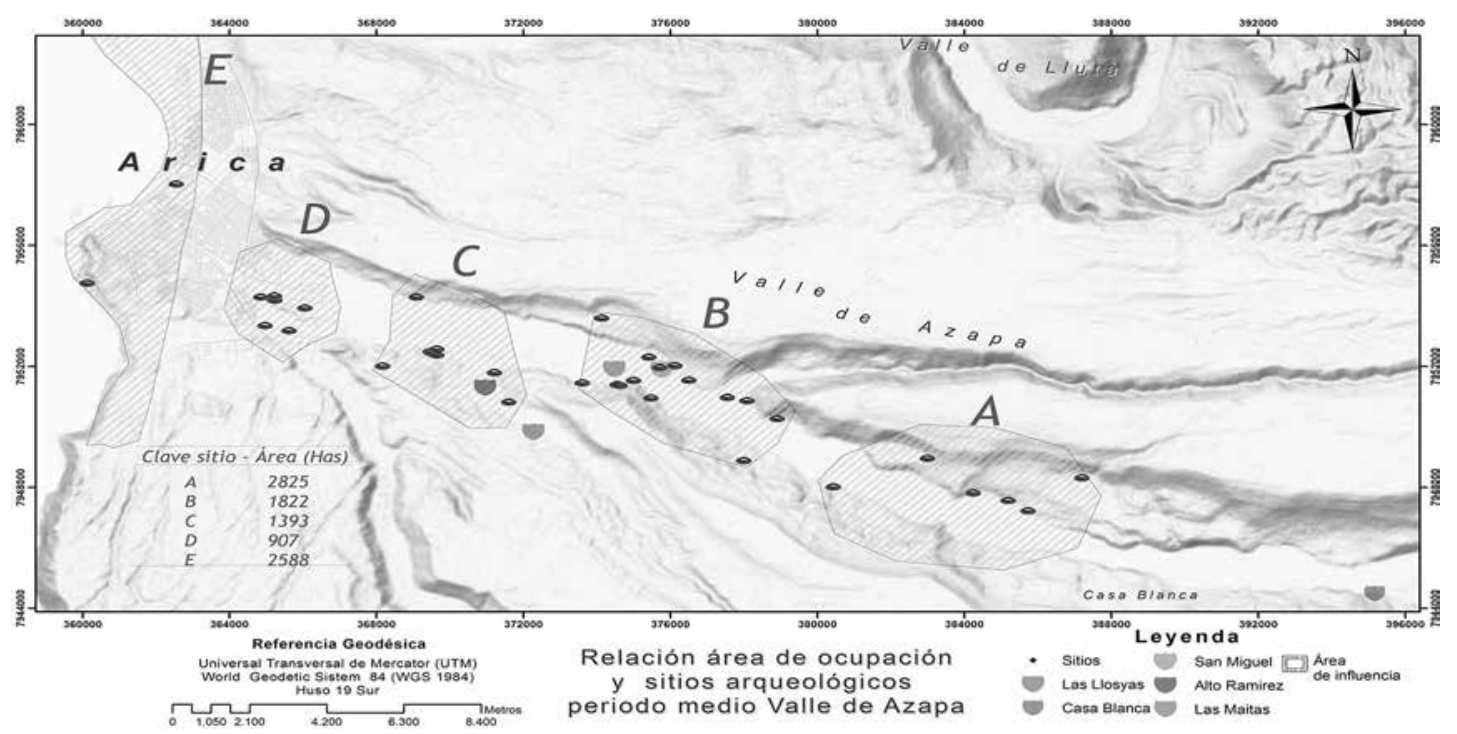

Figura 8. Área de ocupación sitios valle de Azapa.

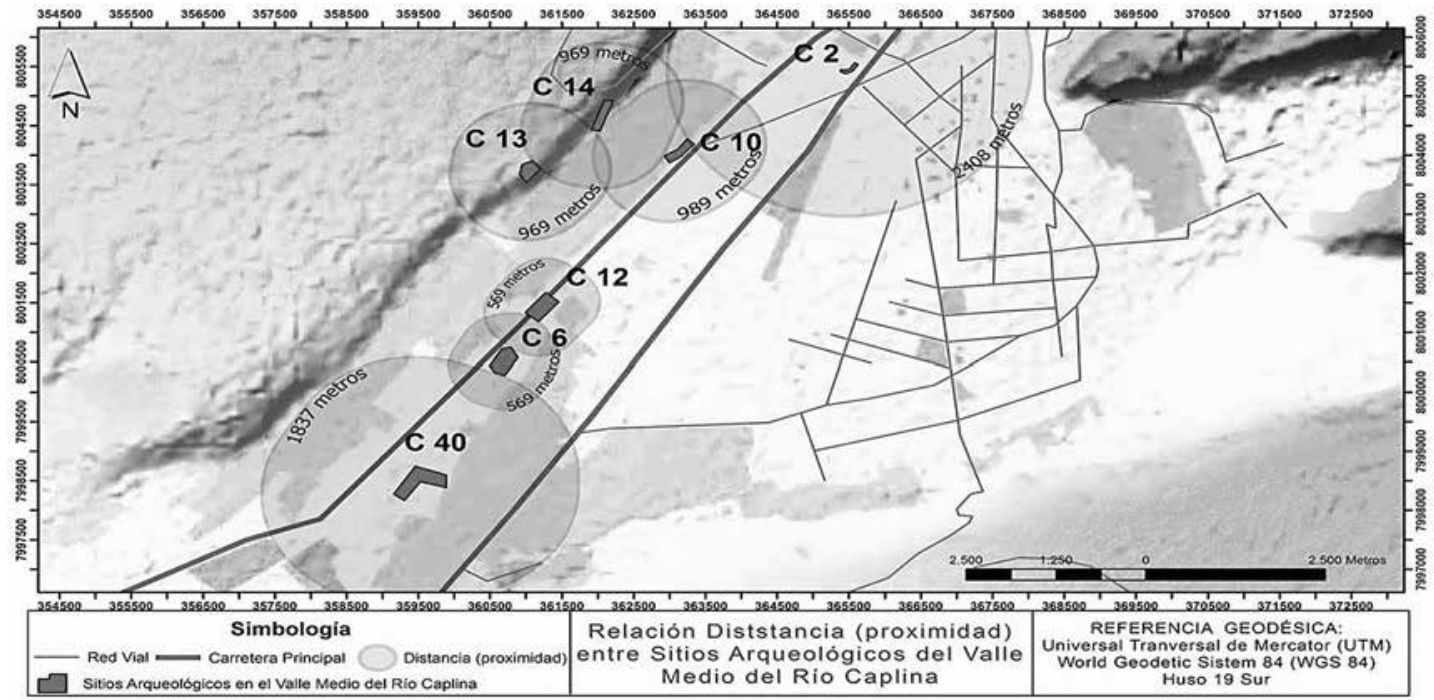

Figura 9. Proximidad entre sitios arqueológicos del valle medio del río Caplina.

\section{Red de drenaje}

En el valle de Caplina, la distribución de los sitios en el área de análisis presenta, en relación con los drenajes principales, un patrón de emplazamiento común para C2, C6, C10, C12 y C40, mientras que para $\mathrm{C} 13$ y $\mathrm{C} 14$ se exhibe una relación de proximidad distinta. En términos generales, predomina la ubicación de los sitios (emplazamiento) entre la quebrada Caramolle y el río Caplina, no obstante para los sitios
C13 y C14 que se localizan en sección de ladera, existe mayor lejanía a los cursos hídricos, siendo el más cercano la quebrada Caramolle (Figura 11).

Para el caso de Azapa el modelo de ocupación observado se presenta uniforme en relación con las zonas de drenaje del área. En los cinco nodos los sitios se emplazan predominantemente en secciones aledañas a los cursos de drenaje, siendo el nodo $\mathrm{E}$ en el que los emplazamientos ocupan sectores más lejanos a estos. La configuración 


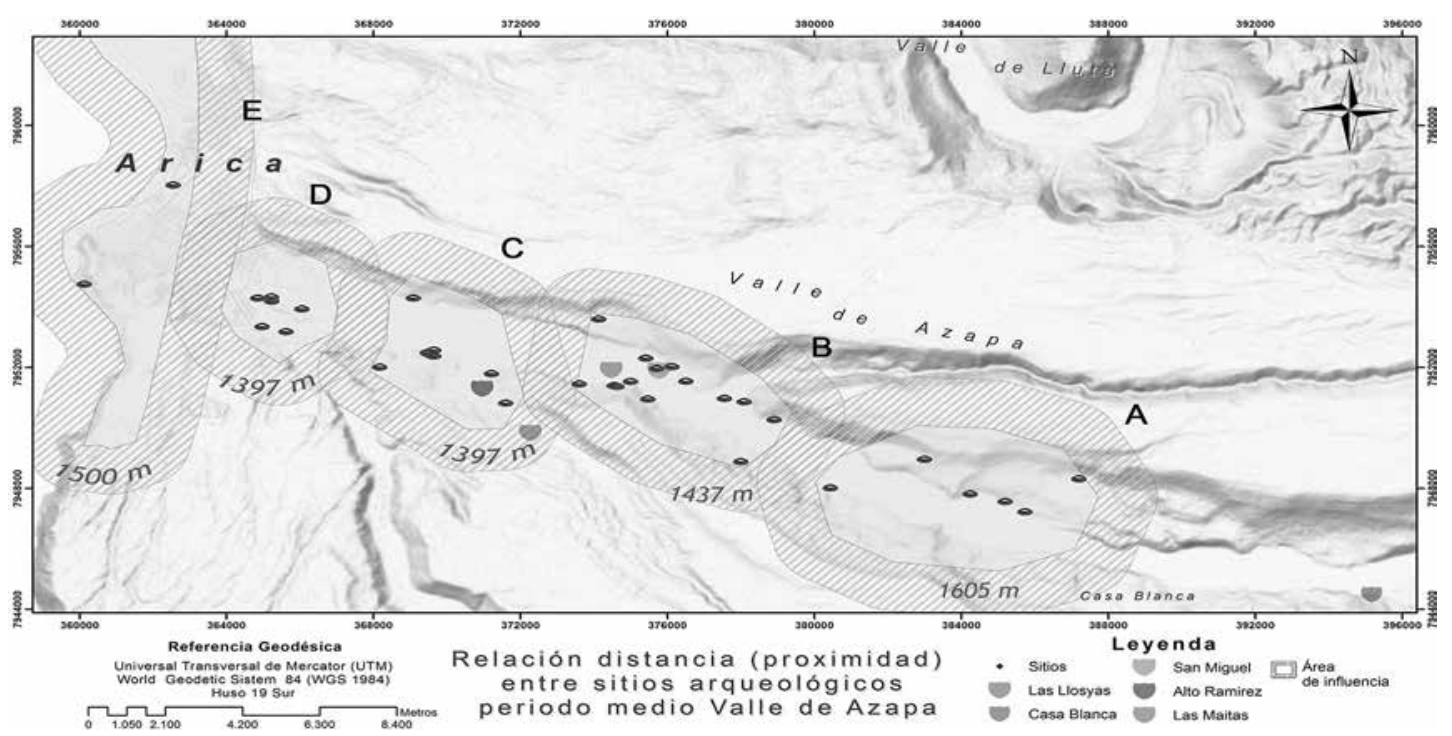

Figura 10. Proximidad entre sitios arqueológicos del valle de Azapa.

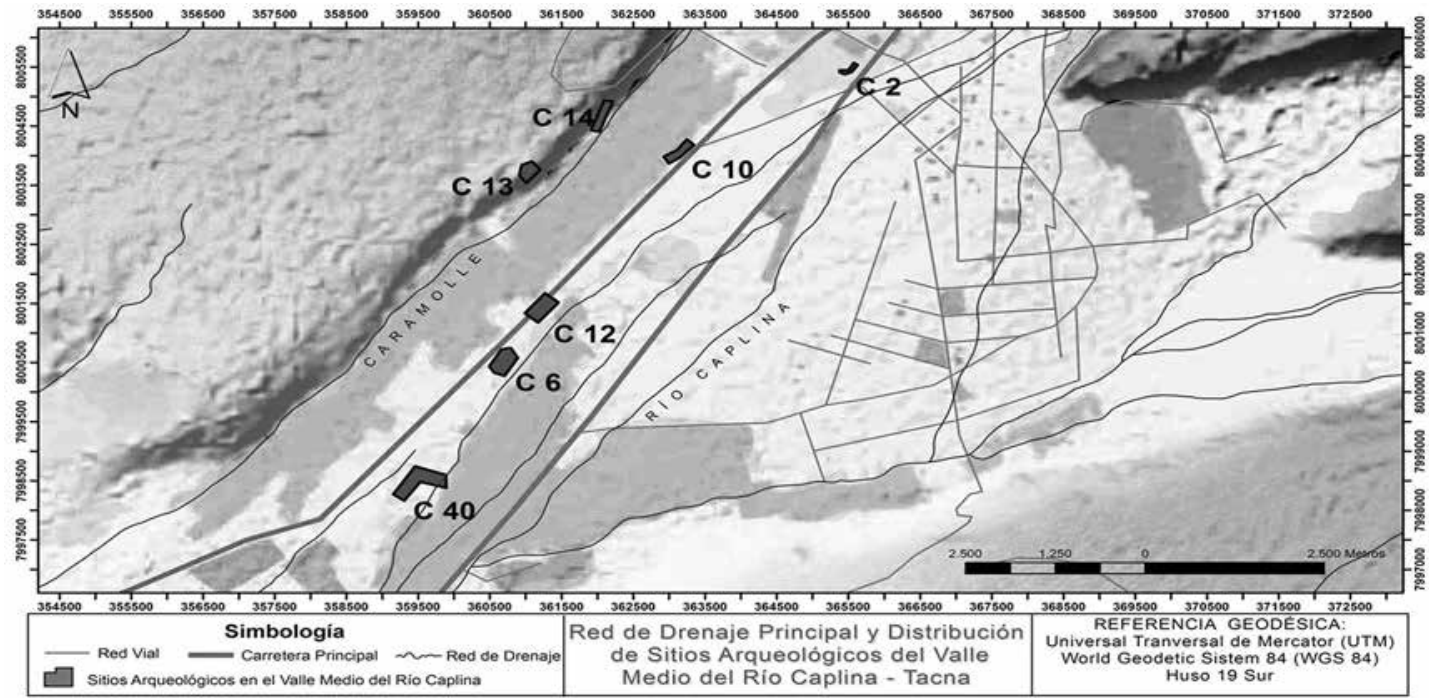

Figura 11. Red de drenaje sección media del río Caplina.

general de emplazamiento de los sitios restantes sigue un patrón de ocupación similar, pero con ubicaciones más cercanas a las zonas de drenaje (Figura 12).

\section{Capacidad de uso mayor de las tierras}

En el valle de Caplina se observa que la distribución de los sitios arqueológicos en el valle medio presenta un emplazamiento preferente sobre tierras con alta calidad agrológica, muy aptas para el cultivo. Los sitios C2, C10, C12, C6 y C40 se localizan sobre una franja de suelos con óptimas capacidades de uso para el desarrollo de la actividad agrícola, estas tierras constituyen la máxima expresión de la agricultura arable, intensiva y apta para el desarrollo de una gran diversidad de cultivos (Figura 13). Además, los sitios C13 y C14 emplazados en sectores de ladera se encuentran localizados sobre "tierras de protección" que 


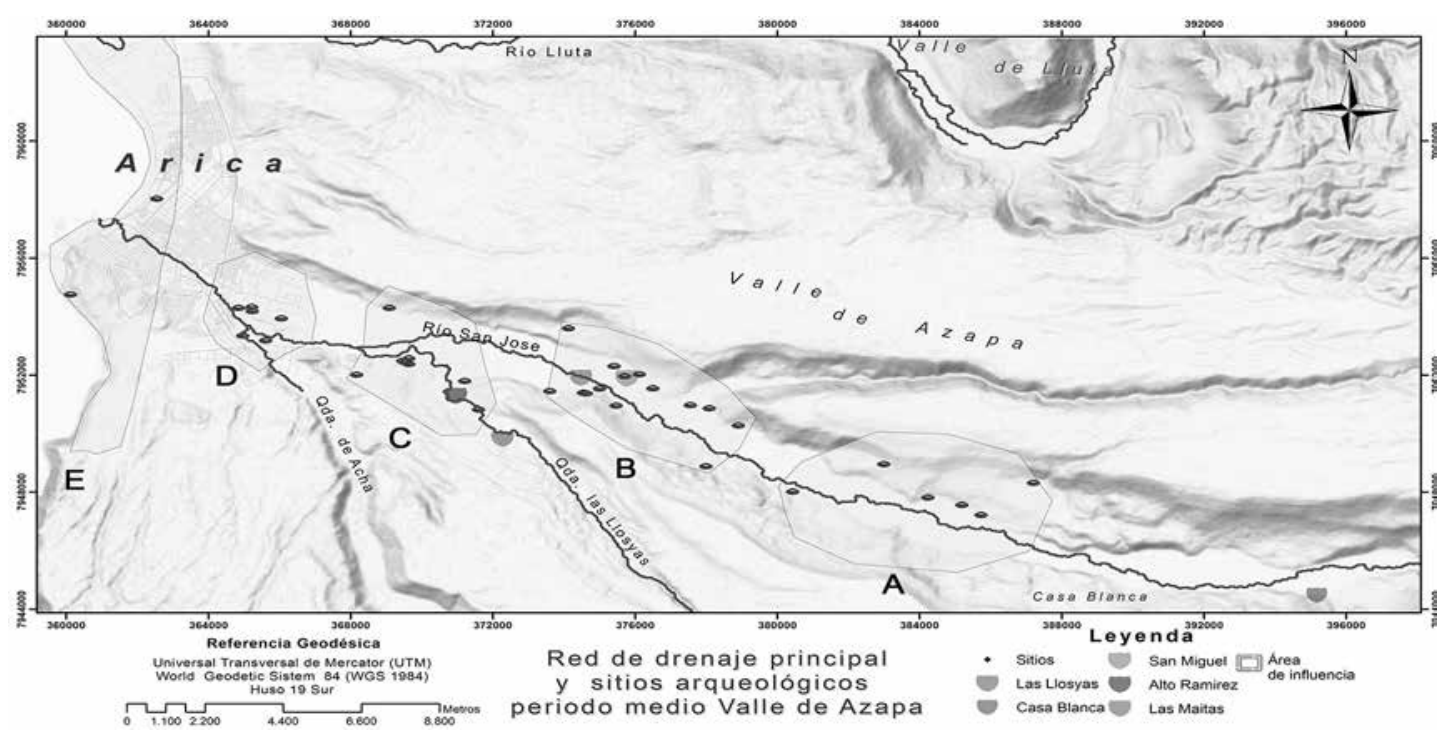

Figura 12. Red de drenaje sección valle de Azapa.

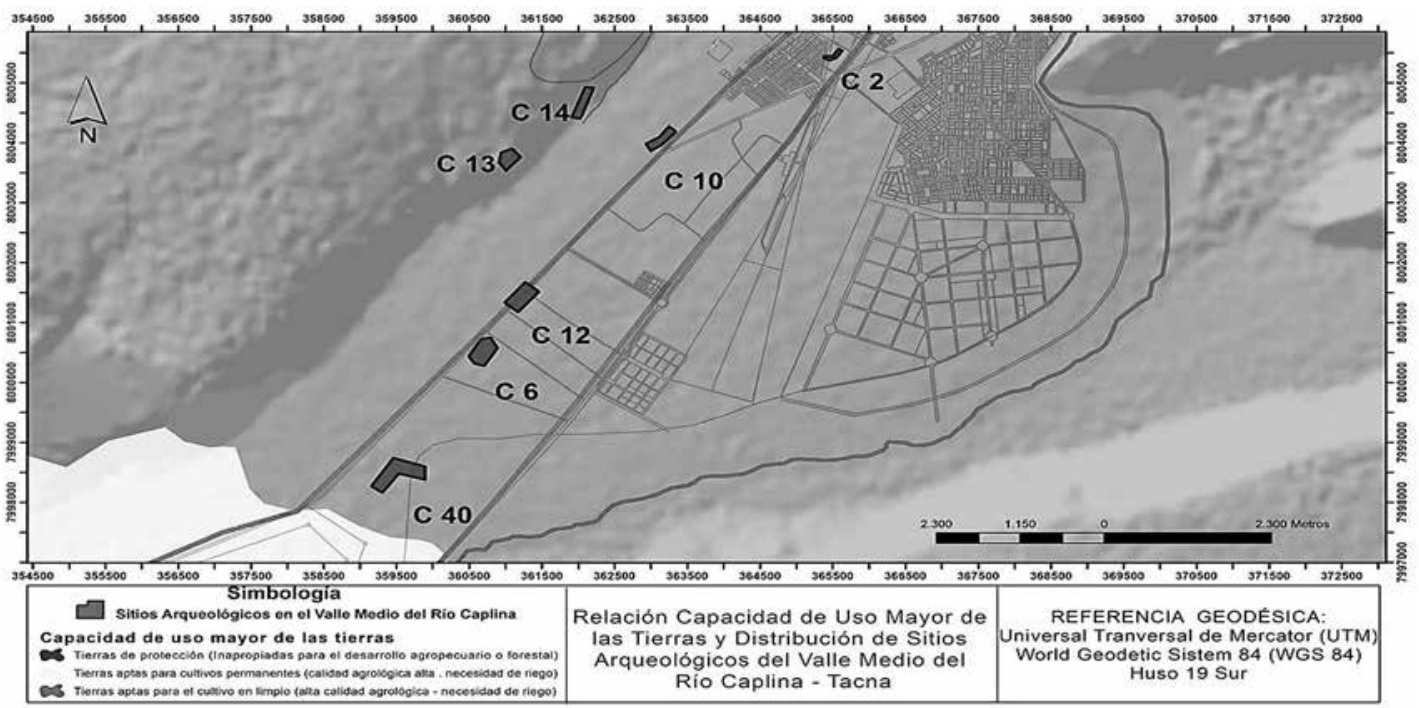

Figura 13. Capacidad de uso mayor de tierras en valle medio del río Caplina.

constituyen tierras inadecuadas para el desarrollo agropecuario o forestal con fines económicos (Oficina Nacional de Evaluación de Recursos Naturales [ONER], 1981).

Para el valle de Azapa los sitios diseminados en el área de estudio presentan un complejo sistema de asociaciones espaciales en torno a las variaciones en la capacidad de suelo actual del valle, se observa una tendencia hacia zonas con capacidad de uso II, III y IV aptas para la actividad agrícola, con limitaciones variables y que agrupan a más del $80 \%$ de los sitios prospectados. Grupalmente, los nodos B y D, que agrupan la mayor cantidad de emplazamientos reconocidos, presentan vinculaciones principales a suelos tipo II y III con bajas y moderadas limitaciones para el desarrollo de la actividad agrícola, mientras que para el resto de las unidades las vinculaciones se presentan diversas y asociadas a suelos con mayores limitaciones para el desarrollo de la agricultura (Figura 14). 


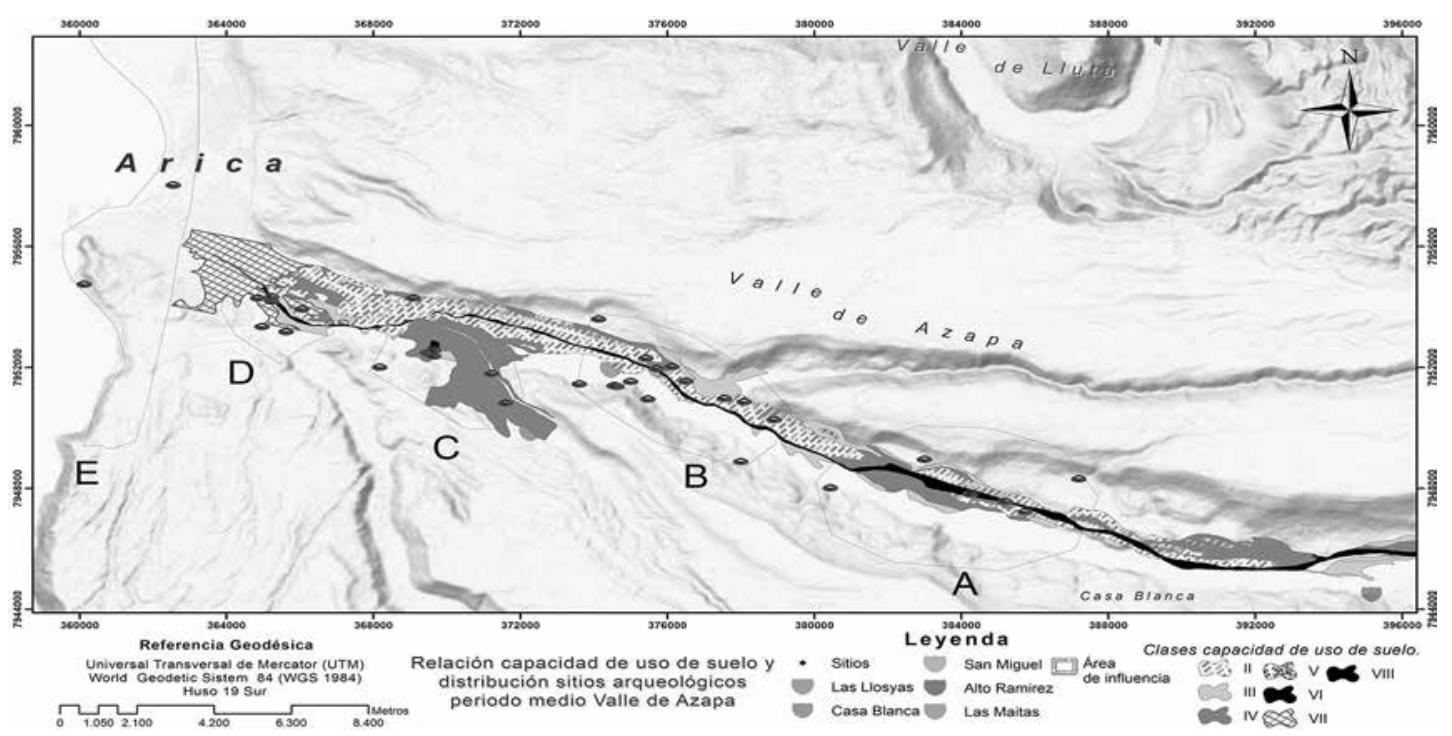

Figura 14. Capacidad de uso de suelo y sitios arqueológicos valle de Azapa.

\section{Discusión}

Los modelos de ocupación espacial observados en los valles de Caplina y Azapa presentan similitudes y diferencias asociadas a las condiciones geográficas del medio en que se asentaron. De acuerdo con los resultados, la distribución de los sitios en el valle de Caplina presenta siete emplazamientos diseminados a lo largo de una extensión aproximada de 10,2 km, con ubicación predominante sobre la sección media del valle a unos $25 \mathrm{~km}$ de la zona costera donde desemboca el río Caplina; por el contrario, en el valle de Azapa la prospección abarcó $18 \mathrm{~km}$, desde la desembocadura del río San José, al interior del valle de Azapa, en el que se identificaron 41 sitios. Tal escenario demuestra que el sistema de ocupación que se presentó en Azapa fue más intenso que en Caplina durante el Periodo Medio.

En relación con las condiciones del relieve, los sitios reconocidos en ambos valles muestran un patrón similar inclinado a la ubicación preferente sobre sectores de baja pendiente, zonas frecuentemente relacionadas a llanuras aluviales aledañas a los cauces presentes en ambos valles. En la misma línea, la altitud a la que se ubicaron los sitios de ambas zonas no supera los $800 \mathrm{msm}$, no obstante, existen diferencias considerables entre las oscilaciones altitudinales presentadas en cada valle, mientras que en el caso de Caplina las diferencias alcanzan 180 m, para el valle de Azapa la fluctuación llega hasta los 686 entre el sitio más bajo y el ubicado a mayor altitud. Estas condiciones responden a la mayor extensión espacial que abarca la ocupación en Azapa, con presencia desde la costa hasta el interior del valle, mientras que en Caplina solo se reduce a una porción no superior a $11 \mathrm{~km}$. En relación con la condición altitudinal, se destaca que para el caso de Azapa la concentración mayor de sitios se identificó entre los 180 a 300 m, área donde se hallan la mayoría de manantiales catastrados, permitiendo un transecto diario entre el sector más amplio del valle con tierras agrícolas y la costa, lo que posibilitó una constante complementariedad con los recursos naturales (Tapia 2014).

Las áreas de los sitios del valle de Caplina son mayores que las del valle de Azapa en cuanto a hectáreas ocupadas, sin embargo, las mediciones obtenidas para los sitios del valle de Azapa son recientes (2011), por ello se presume la alteración de varios de estos asentamientos durante los últimos tres decenios, debido a labores agrícolas. Por lo demás, al considerar a los sitios de Azapa en nodos de concentración homogéneos el escenario se presenta diametralmente opuesto, ya que las áreas de ocupación son mucho mayores para el valle de Azapa.

En cuanto a las distancias se observa que en el valle de Caplina, a pesar de que el número de sitios prospectados es menor que en Azapa, existe una mayor distancia entre ellos. No obstante y similar al caso de las áreas de ocupación, al considerar los 
sitios de Azapa agrupados en nodos, las distancias se equiparan presentando valores de proximidad similares entre los emplazamientos de ambos valles.

En relación con las redes de drenaje, los valles presentan patrones de ocupación similar con predominancia de sitios emplazados en sectores aledaños a los cursos de drenaje como una constante dentro de las áreas estudiadas. No se reconoce sitio alguno ubicado en zona de drenaje, situación que da cuenta del conocimiento que poseían las sociedades del medio que ocuparon, ya que estos sectores se encuentran expuestos a inundaciones esporádicas por flujos de agua, lo que los hace menos atractivos para el establecimiento permanente de un asentamiento.

El último factor condicionante que permite aproximarse al escenario que afrontaron las comunidades humanas para asentarse en las zonas bajas del valle de Azapa y media del río Caplina, es el suelo. Este se presentó generalmente favorable en ambos valles cuando se asoció a la ubicación de un sitio, porque tanto en Azapa como Caplina los suelos con menores limitaciones para el desarrollo agrícola fueron los que presentaron mayor ocupación. En este sentido, el patrón de asentamiento es bastante claro en ambos valles, presentando una sólida asociación entre la ocupación y los sectores que bridaban mayores oportunidades para el desarrollo agrícola.

Estos sistemas de ocupación responden, además, a patrones culturales como en el valle del Caplina, donde la presencia de Tiwanaku fue mayor, interactuando con las poblaciones locales entre ellas Maitas y San Miguel, a diferencia de lo que ocurre en el valle de Azapa, donde la presencia Tiwanaku se observa más tardía (900 al 1200 d.C.), por lo tanto, entre comienzos de la era cristiana y los 600 d.C. se visualiza un marcado poblamiento local sustentado sobre la base de la economía agrícola, complementada por la pesca y recolección. Este proceso agrícola va a tener su máxima expresión arquitectónica con la construcción del poblado de San Lorenzo, lo que lo habría llevado según Muñoz y Focacci (1985) a cumplir funciones de centro administrativo y ceremonial, espacio que además habría articulado la economía en el sector bajo donde convergieron los agricultores del valle y pescadores de la costa de Arica.

\section{Comentarios finales}

El análisis de las condiciones geográficas asociadas a las características presentadas por los emplazamientos en ambos valles invita a inferir que la poblaciones asentadas fueron agricultoras, configurándose espacialmente para aprovechar de la mejor manera las oportunidades que ofrecía el medio. En consecuencia, la ocupación predominó sobre lugares abiertos y estratégicos, cercanos a los recursos hídricos y con buenas posibilidades para la obtención de agua, maderos, fibras vegetales, piedras de río, etcétera.

Es indiscutible que el sistema de ocupación espacial más complejo se presentó en el valle de Azapa, donde el poblamiento humano se articuló a partir de los recursos manantiales, esta forma de agruparse a partir de estos "ojos de agua" ayudó a que se establecieran asentamientos nodales donde el centro neurálgico fue el manantial, acompañada de los cementerios donde estaban enterrados los ancestros, no así las viviendas, que más bien fueron lugares de refugio nocturno y por lo tanto las evidencias arqueológicas son menores, situación que habría cambiado cuando se estructura el centro administrativo de San Lorenzo. La cercanía con la costa permitió que la población explotara los recursos marítimos, que junto con la agricultura se constituyeron en los pilares fundamentales donde se estableció la población aldeana.

Por último, la observación de las condiciones geográficas en ambas zonas (Azapa y Caplina) nos plantean la configuración de un paisaje social donde el grueso de la población tuvo como actividad central la agricultura. Esta actividad económica fue consecuencia de un largo proceso que se remonta a partir del último milenio antes de Cristo, siendo responsables directos los pescadores asentados en el litoral del Pacífico, quienes de manera complementaria explotaron estos valles por medio de la caza y recolección terrestre desde los 9000 años (Muñoz 2010).

\section{Agradecimientos}

Este artículo es producto de la investigación desarrollada en el proyecto Fondecyt 1130249. Se reconoce el apoyo del Convenio de Desempeño Universidad de Tarapacá-Mineduc. Se agradece la colaboración del Sr. José Raúl Rocha encargado de la Oficina de Catalogación del Departamento de Antropología de la Universidad de Tarapacá con quien prospectamos y discutimos la problemática del valle de Azapa. 


\section{Referencias Citadas}

Botero, P. León, J. y Moreno J.

1989 Suelos y Grandes Paisajes. En Cacicazgos Prehispánicos del Valle de la Plata, Tomo 1 El Contexto Medio Ambiental de la Ocupación Humana, editado por L. Herrera, R. Drennan y C. Uribe, pp. 1-14. Center for Comparative Arch, Pittsburgh.

Clark. G.

1980 Arqueología y sociedad. Ediciones AKAL, Madrid.

Córdova, $\mathrm{H}$.

2002 Naturaleza y Sociedad: Una Introducción a la Geografía. Fondo Editorial PUCP, Lima, Perú.

Cruz, A.

2010 Servicio de consultoría para la identificación de fuentes de contaminación en la región Tacna, línea Base del río Caplina (4 de junio). http: //consultorias.minam.gob. pe: 8080/bitstream/123456789/89/1/CD000053.pdf (20 diciembre 2014).

Dauelsberg, P.

1995[1959] Contribución a la arqueología del valle de Azapa. Boletín del Museo Regional de Arica 3. Reedición Boletines. Arica.

Del Moral, J.

1999 Historia y ciencias humanas sobre metodología y didáctica. Huerga y Fierro Editores, Madrid.

Dirección de Obras Hidráulicas

2002 Estudios Agronómicos Básicos de los Valles de Lluta, Azapa, Vitor y Camarones. Dirección de Obras Hidráulicas. (DOH). Santiago.

Espoueys, O.

1974 Archivo: inventario de sitios arqueológicos en los valles de Arica. Oficina de Registro, Museo San Miguel de Azapa, Departamento de Antropología, Universidad de Tarapacá.

Focacci G.

1990 Excavaciones Arqueológicas en el Cementerio Az-6. Valle de Azapa. En: Chungara 24-25: 69-124.

Goldstein, P.

1995-1996 Tiwanaku settlement patterns of the Azapa Valley. En: Diálogo Andino 14-15: 57-73.

González, F. Riquelme A. Contreras P. y Mazuela, P.

2013 Antecedentes generales para la sustentabilidad de la producción hortícola en el valle de Azapa, Arica, Chile. Idesia 31: 119-123.

Gordillo, J.

1993 Catastro, Inventario y Evaluación de Sitios Arqueológicos en el Valle Medio del Río Caplina-Tacna. Tesis de Licenciatura. Universidad Católica Santa María, Arequipa.

Hidalgo, J.

2004 Historia andina en Chile. Editorial Universitaria, Santiago, Chile.

Instituto Nacional de Recursos Naturales

1992 Diagnóstico de infraestructura de captación de aguas subterráneas-cuenca caplina (5 de junio). http: //cid.ana. gob.pe/ana/sites/default/files/Cuenca\%20Caplina.pdf (4 diciembre 2014)

Llagostera, A.

1999 Sociedades del Sur Andino: los desiertos del Norte y el Centro húmedo. En Historia general de América Latina I: Las sociedades originarias, editado por T. Rabiela y J. Murra, pp. 445-464. Trotta, Paris.
Lumbreras, L.

1999 Tribus y Estados en los Andes: Siglos XII-XVI. En Historia de América Andina: Las sociedades aborígenes, editado por L. Lumbreras, pp. 331-434. LIBRESA, Quito.

Muñoz, I y F. Zalaquett

2011 El paisaje en la distribución de los túmulos funerarios del valle de Azapa, durante el periodo formativo, norte de Chile. Revista de Geografía Norte Grande. Vol. 50: 23-43. 201.

Muñoz I y F. Zalaquett

2014 El paisaje en el ordenamiento territorial prehispánico durante el Periodo Medio, valle de Azapa, norte de Chile. Revista de Geografía Norte Grande. V60: 21-62.

Muñoz, I.

2010 Tempranas ocupaciones humanas en la costa desértica del Pacífico Sur: El caso de Acha-2. III Simposio Internacional del Hombre Temprano en América. 175192. Editado por J. Jiménez, C. Serrano, A. González y F. Aguilar. Instituto Nacional de Antropología e Historia, Universidad Nacional Autónoma de México y Museo del Desierto A.C.

Muñoz, I. y G. Focacci

1985 San Lorenzo: testimonio de una comunidad de agricultores y pescadores postiwanaku en el valle de Azapa (Arica-Chile). Chungara 15: 7-30.

Oficina Nacional de Evaluación de Recursos Naturales (ONER). 1981 Inventario nacional de tierras del Perú. Lima.

Rivera, M.

1983 Patrones prehistóricos y contemporáneos del uso de la tierra en el valle de Azapa. Norte de Chile. Diálogo Andino 2: 9-21. Arica.

Sánchez, A y Morales, L.

1990 Las regiones de Chile. $3^{\mathrm{a}}$, Editorial Universitaria, Santiago, Chile.

Santoro, C.

1980 Estudios de un yacimiento funerario arqueológico del extremo norte de Chile, 1300 a.C.-1300 d.C. Tesis no publicada para optar al título de arqueólogo. Antofagasta: Departamento de Arqueología, Universidad del Norte.

Segrelles, J.

2002 Geografía humana: fundamentos, métodos y concepto. Editorial Club Universitario, Alicante.

Sugiura, Y.

2005 Y atrás quedó la ciudad de los dioses: historia de los asentamientos en el Valle de Toluca. UNAM, D.F, México. Tapia A.

2014 Marco geográfico natural del valle de Azapa y la costa de Arica. En mil años de historia de los constructores de túmulos de los valles desérticos de Arica: Paisaje, Monumentos y Memoria. Editores Iván Muñoz y Soledad Fernández. Pp. 23-38. Ediciones Universidad de Tarapacá

Torres, A. y Acevedo, E.

2008 El problema de salinidad en los recursos suelo y agua que afectan el riego y cultivos en los valles de Lluta y Azapa en el norte de Chile. Idesia 26: 31-44.

Venegas, $\mathrm{R}$.

2007 Aptitud territorial: una aproximación hacia la planeación y el ordenamiento del territorio. Universidad Autónoma de Baja California, México. 


\section{Notas}

1 Se tomó la determinación de agrupar los sitios por nodos, ya que la información catastrada por el Museo Regional de Arica en la década de 1950 solamente hace referencia a la ubicación de los yacimientos, no así a la extensión y área de los sitios, además, la prospección del 2014 arrojó una información parcial, ya que el $90 \%$ de los asentamientos (sitios) se hallan disturbados y arrasados por la maquinaria agrícola, por tanto la información que se obtuvo es parcial. 